\title{
Carta del editor
}

Al dirigirme por primera vez a los lectores de Cuadernos de Medicina Forense como editor de la revista, responsabilidad que asumí a mediados del pasado mes de junio, debo ante todo agradecer la confianza de la Junta Directiva de la AMFA, representada por su presidente, Patricio Barrero Raya, por lo que constituye un honor y un privilegio. Por otra parte, quiero dejar patente mi reconocimiento a la gran labor realizada durante muchos años en la revista por Joaquín Lucena, que ha dejado una obra muy difícil de igualar.

Se ha producido también una importante renovación en el consejo editorial y en el consejo asesor, con la incorporación de nuevos especialistas, a quienes doy la bienvenida y agradezco de antemano su colaboración. También quiero dar las gracias a los que venían trabajando intensamente en el anterior equipo editorial, de quienes espero, y de hecho ya estoy obteniendo, una gran ayuda: Antonio Rico, Imanol Garamendi y muchos más. De los nuevos miembros del cuadro editorial, hay un nombre que no puedo dejar de citar por ser un valor fundamental en esta nueva etapa de la revista. Hace más de dos décadas que trabajo codo a codo con Valentín Ramos en el ejercicio práctico y en la enseñanza de la medicina forense. Con esfuerzo y rigor estamos intentado, y creo que consiguiendo, que muchas labores en nuestro entorno se hagan con unos parámetros que superarían los más exigentes niveles de garantía de calidad.

Aunque tengo cierta experiencia en la elaboración de publicaciones y en procesos de revisión editorial, carezco de experiencia formal como editor. La prudencia, el entusiasmo y la honestidad espero me ayuden a superar las dificultades.

Por numerosos motivos, Cuadernos de Medicina Forense se encuentra en un momento difícil. Quizá una de las cuestiones más importantes sea la falta de artículos, debido a mi juicio al gran esfuerzo que conlleva la elaboración de un trabajo; esfuerzo que posteriormente no se ve compensado para el colectivo de médicos forenses con una carrera profesional o posibilidades de promoción de los más jóvenes. Así, publicar en revistas científicas se ha convertido en la actualidad, para los médicos forenses, en poco más que altruismo. Confío en que este altruismo tenga alguna vez su recompensa.

En nuestra intención de despertar el interés de los lectores, hemos decidido incluir, a partir de ahora, una nueva sección titulada Formación continuada, en la cual tendrán cabida guías de actuación profesional o cualquier otra recomendación actualizada en medicina forense, de carácter eminentemente práctico; trabajos de lectura rápida y útiles para la resolución de problemas frecuentes en el ejercicio profesional, de especial interés para los jóvenes médicos forenses y como puesta al día para los experimentados.

Consideramos importante fomentar la sección Correspondencia, con cartas al editor relacionadas con artículos previamente publicados en la revista (los autores del artículo tendrán derecho de réplica). En esta sección incluimos como novedad Cartas científicas, mediante las que podrán comunicarse nuevos estudios de medicina forense que sean adecuados para exponerse de manera breve.

También trataremos de incrementar el número de trabajos relacionados con las áreas de la medicina legal que absorben la mayor parte de la actividad profesional de los médicos forenses (valoración del daño corporal, psiquiatría, mala praxis profesional sanitaria, bioética) y con otros campos profesionales relacionados con la medicina forense (criminología y toxicología forense).

Dejo para el final lo más importante: dar las gracias a ustedes, los lectores, por haber dado a la revista el bien más preciado que pueden concederle: su tiempo. Gentileza que espero sigan manteniendo en el futuro.

\author{
JL. Palomo Rando \\ Editor-Jefe de Cuadernos \\ de Medicina Forense \\ Jefe de Servicio de \\ Patología Forense \\ Instituto de Medicina \\ Legal. Málaga
}

